\title{
Music therapy for preterm infants and their parents during NICU stay and beyond: current recommendations for clinical practice in Poland
}

There is preliminary evidence that music therapy plays a beneficial role for preterm infants and their primary caregivers during the neonatal period; however, available research considers mostly cohorts from North and South Americas, Australia, Israel and certain western European countries, excluding Poland. Remembering that music, and therefore music therapy, is highly culturally dependent, there is no "perfect program package" that can be directly applied across all communities to achieve desired effects everywhere. The commencement of the multi-center international randomized controlled trial, Longitudinal Study of music Therapy's Effectiveness for Premature (LongSTEP) infants and their caregivers, has provided the impetus for Polish music therapists to begin offering music therapy services in neonatal intensive care units as a part of clinical research.

Since research on music therapy dedicated to premature babies and their families is only beginning to emerge in
Poland, there is a call to develop a culturally and contextbased approach that can be implemented in Polish neonatal settings. The objective of this perspective article is to present recommendations for clinical practice with premature babies and their families based on available international research and practical guidelines, as well as national experiences from the LongSTEP trial that make it culturally appropriate.

This paper might be of great interest to readers interested in implementing music therapy interventions with local conditions and opportunities to improve outcomes for a "real-world" impact.

KEY WORDS

music therapy; NICU; recommendations; evidence-based practice

ORGANIZATION - 1: GAMUT - The Grieg Academy Music Therapy Research Centre, NORCE Norwegian Research Centre AS, Norway · 2: Institute of Psychology, University of Gdansk, Gdansk, Poland · 3: The Karol Szymanowski Academy of Music, Katowice, Poland · 4: Department of Children's Creativity and Expression in Pedagogy, Faculty of Pedagogy and Psychology, University of Silesia, Katowice, Poland

aUthors' contributions - A: Study design - B: Data collection - C: Statistical analysis - D: Data interpretation .

E: Manuscript preparation · F: Literature search · G: Funds collection

CORResponding AUthor - Łucja Bieleninik, Ph.D., Institute of Psychology, University of Gdansk, 4 Bażyńskiego Str., 80-309 Gdansk, Poland, e-mail: lucja.bieleninik@ug.edu.pl 


\section{BACKGROUND}

\section{PREMATURITY}

The Global Action Report on Preterm Birth stated that more than 1 in 10 of the world's newborns are born prematurely, corresponding to 15 million preterm infants each year (March of Dimes, 2012). All births occurring before 37 completed weeks of gestation (or fewer than 259 days from the first day of a woman's last menstrual period) fall into the category of premature birth according to the World Health Organization definition (WHO, 1977). The total burden is classified into the following subdivisions: extremely preterm ( $<28$ weeks of gestation), very preterm $(28-<32$ weeks) and moderate preterm (32 - $<37$ completed weeks of gestation, sometimes split for late preterm - $34-<37$ completed weeks) (March of Dimes, 2012). The more extreme the prematurity is, the more adverse are the consequences; however, regardless of gestational age (GA), all preterm babies are at increased risk of health-related problems and adverse developmental outcomes over lifespan. These include respiratory distress syndrome, retinopathy of prematurity, and infection, as well as long lasting sequelae: cerebral palsy, intellectual and learning impairments, psychiatric and behavioral disorders, vision and hearing deficits and loss, chronic lung disease and long-term cardiovascular problems (Bidzan \& Bieleninik, 2013; Blencowe et al., 2013). Research has shown that premature birth has an impact on the children's future physical, cognitive, emotional and behavioral functioning (Bernard-Bonnin, 2004; Huhtala et al., 2012; Miles, Holditch-Davis, Schwartz, \& Scher, 2007; Singer et al., 1999). It is also likely that prematurity is linked with significant public health and society costs which include increased expenses for neonatal care, long-term costs associated with complex health status, and lost economic productivity over life (Underwood, Danielsen, \& Gilbert, 2007).

Most neonates who were born before 28 weeks would not survive without neonatal intensive care, and those born within 28-32 weeks also need special care (Blencowe et al., 2013); therefore, they often require a prolonged convalescence period while hospitalized in neonatal intensive care units (NICUs). It should be highlighted that not only the care of a neonate, but also the care of the woman before, during, and after her pregnancy, creates the effective continuum of care in this area (March of Dimes, 2012). Consequently, regarding the first weeks of the child's life, the whole family should be taken care of. NICU stay could be a traumatic and stressful event for parents and might adversely impact both parental and children's mental health as well as the process of healthy bonding between them (Bidzan, Bieleninik, Zdolska, \& Salwach, 2009; Bieleninik, 2012; Bieleni- nik, Bidzan, \& Salwach, 2009). The preterm birth and subsequent hospitalization can impair the motherinfant relationship, which plays a central role in the child's socio-emotional development and formation of future intimate relationships (Ainsworth, Blehar, Waters, \& Wall, 1978; Bowlby, 1997). At the same time, all parents who have been affected by preterm birth need to adapt to a new role, i.e. 'being a preterm baby's parent', for which they have not managed to get prepared during the pregnancy due to its shorter duration (Bieleninik, 2012). Families can experience higher levels of parenting stress, anxiety, as well as many crises, insecurity and powerlessness (Bieleninik, 2012) and financial difficulties (Berard, Le Tiec, \& De Vera, 2012; Singer et al., 1999). Therefore, psychosocial support for the whole family is required as an element of the NICU environment these days.

\section{POLISH HEALTH SYSTEM AND NICUs}

Poland is a European Union (EU) Member State with a population of almost 38 million. The public health system consists of the Minister of Health and local government units: territorial self-government. The funds are gathered by mandatory insurance premiums and operated by the National Health Fund (NFZ) (Sowada et al., 2019). In 2018 there were 375 neonatological units in Poland (https://bdl.stat.gov.pl/BDL/ dane/podgrup/tablica). Since 1997, three-level selective perinatal care is functioning, which means that both maternity and neonatal units are categorized as follows: reference level I - for natural births with no complications expected; reference level II - for pregnancies with pathology and higher risk for the baby; reference level III - for high risk pregnancies and births, including preterm. According to Polish norms, NICU rooms house from 4 to 10 incubators and the optimal distance between incubators is $3 \mathrm{~m}(2 \mathrm{~m}$ is the minimal distance) (Pilewska-Kozak et at., 2009).

The estimated global preterm birth rate for 2014 was $10.6 \%$, while in Poland it was approximately $6 \%$ (Blenclowe et al., 2013; Troszyński, Niemiec, \& Wilczyńska, 2009). The number of perinatal deaths in Poland is decreasing (Troszyński et al., 2009); however, the level of medicalization of birth in Poland is considered too high (Doroszewska, 2017) and - similarly to other middle-income EU countries - there is a growing interest in more "humanized" and family-oriented approaches in neonatological community (EuczakWawrzyniak, Czarnecka, Konofalska, Bukowska, \& Gadzinowski, 2010).

The most current version of standards of medical care for neonates (Borszewska-Kornacka, 2019) includes recommendations regarding the development of newborn being hospitalized in NICU and a chapter on supporting parents of preterm babies. On the subject of situating the family in the NICU context, 
engaging parents early, assisting rather than replacing them in care of the child all the while supporting bonding between them are recommended. Offering available and honest information on the health status of the child, together with psychological and educational support for parents of preterm babies, is also recognized as a highly important part of care. Recommendations regarding the development of a child are focused on appropriate sensory stimulation: sounds, touch, light and positioning. It is related to current knowledge about the parent's attuned care as a regulator of the infant's brain development; the voices of mother and father are crucial in the interplay between parents and infants, and are considered the primary source of bonding, together with other stimuli, such as touch, eye contact, smell, taste and movement (Hart, 2011).

In the abovementioned standards, the following scales which are suggested for observing the neonates in NICUs are listed: Neonatal Behavioral Assessment Scale, Newborn Individualized Developmental Care and Assessment Program, Assessment of Preterm Infants' Behavior. However, specific procedures that accommodate the needs of families and are not only appropriate but also feasible in the Polish health care system and cultural context still need to be developed. From Polish parents' perspective psychological support is considered crucial at this difficult period of time and the provided care does not address their needs fully (Kopeć, Aftyka, Humeniuk, Rybojad, \& Rozalska-Walaszek, 2016).

In this context it can be observed that the familycentered model of care is currently in the process of being implemented in the Polish health care system. Family centered care (FCC) is an inclusive approach to caring for each patient individually, which is directed towards meeting the needs of all the members of family systems. It brings benefits to babies, parents and medical team as well, and is currently considered not to be an optional choice, but the foundation of the best care possible. It is recommended by major perinatal professional organizations such as Neonatal-Perinatal Section of the American Academy of Pediatrics (AAP) (Hall, Philips, \& Hynan, 2016). In Europe, the quality of FCC differs widely between countries and specific units (Separation and Closeness Experiences in Neonatal Environment (SCENE) research group, 2016). The principles of FCC include the following: dignity and respect, information sharing, participation and collaboration in care (Institute for Patient and Family-Centered Care, 2010). Following this approach, the care is planned around the needs of the entire family: instead of being limited to the child only, it also targets other family members as care recipients. The care should therefore be culturally appropriate and provided in collaboration between parents and medical health care providers (Jolley \& Shields, 2009). FCC is therefore the aim to be achieved in Polish neonatal units, which still needs to be worked towards. Music therapy (MT) can play a role in this process, and help in making Polish neonatal units, including NICUs, more family-oriented.

\section{MUSIC THERAPY FOR PREMATURE BABIES AND THEIR FAMILIES - THEORETICAL CONSIDERATIONS}

Music therapy in neonatal units consists of "the informed use of music and aspects of a therapeutic relationship to promote optimal infant development and facilitate secure attachment with primary caregivers" (Bieleninik, Ghetti, \& Gold, 2016, p. 2). MT in the NICU environment is usually applied in accordance with the Newborn Individualized Developmental Care and Assessment Procedure (NIDCAP) (Abromeit, 2003), which recommends that interventions should be individualized, provide balanced sensory stimulation, and involve primary caregivers. The goals of MT in neonatal practice might be related to three aspects: infants', parents', and family system's needs. They include the following benefits: supporting infant's development in neurobehavioral and sensory areas by providing individualized MT activities; increasing social, emotional, cognitive, motor, and communication competencies in developmentally appropriate ways; engaging and supporting family, especially parents, by providing opportunities for infant-parent interaction and enhancing bonding (Hanson-Abromeit \& Colwell, 2010). There is nothing like "gold program packages" in MT dedicated to premature children. Review of "best practices" or "the most common practices" in MT includes techniques based on listening to prerecorded music (Auditory Stimulation with the Mother's Voice, Individually Provided Sustained Music, Music-Reinforced Nonnutritive Sucking), using live music making (such as Creative Music Therapy for Premature Infants and Their Parents, Song of Kin, Breathing Entrainment, Singing as Entrainment, Environmental Music Therapy, Contingent Singing), and using some combined music in different forms with additional stimuli, such as touch or visual components (Multimodal Stimulation with Music) (Nocker-Ribaupierre, 2013). Selection and application of effective MT approaches is done by decision-makers, practitioners, and program funders who have to choose among all available techniques that address complex and challenging problems of prematurity. Sometimes approaches are merged together and used in an eclectic way in order to meet the individual needs of each child and family. In general, voice is used mostly in the NICU environment, and the characteristics of uses are as follows: smooth, descending melodic contours, slow tempo, steady pulse, repetitive and
Music therapy for preterm infants: recommendations for clinical practice in Poland 
Łucja Bieleninik, Ludwika Konieczna-Nowak, Sara KnapikSzweda, Justyna Kwaśniok simple rhythms, no accompaniment (Smith, Caine, \& Hanson-Abromeit, 2018).

In this context of FCC, the music therapist who is specialized in neonatal MT, instead of providing interventions by themselves, guides the parents how to sing and use their own voices in the ways that promote bonding between them and a child, co-regulation, interaction, communication, as well as neurological development of a baby in the NICU environment and beyond. Singing is used here as a developmental stimulus and also as a medium for sharing positive emotions, closeness and love. Parents who do not feel comfortable with using their voices are encouraged and coached to do so in the infant-directed way. As the family's histories are highly respected and treated as resources, the repertoire choices made by the music therapist should be sensitive to the cultural backgrounds and personal preferences of parents (Ullsten, Gaden, \& Mangersnes, 2019).

\section{EVIDENCE-BASED MUSIC THERAPY DURING NICU STAY AND AFTER DISCHARGE}

To our knowledge, as yet MT is not considered an element of standard care in any country in the world. However, there are places (such as the USA, Germany and Switzerland) where strong music therapy programs exist in the neonatal area. There are also countries where just a few programs exist, but which are nevertheless relevant, for example Australia, Colombia or the Nordic countries. Some resources have been devoted to conduct research regarding MT for newborns hospitalized in neonatal settings for over 20 years, and approaches and strategies that work have been identified internationally. In very few cases practical recommendations or frameworks were formulated (German speaking countries and Switzerland - Haslbeck, Nöcker-Ribaupierre, Zimmer, Schrage-Leitner, \& Lodde, 2018; the USA - Standley, 2003; Smith et al., 2018).

However, there still is a need to increase access to practices based on the paradigm of evidence-based practice (EBP) considering MT dedicated to preterm children. It seems important, however, to define the understanding of evidence-based practices that we follow in this paper. In this matter we respect the interpretation given by the American Psychological Association (American Psychological Association, Presidential Task Force on Evidence-Based Practice, 2006), which requires "the integration of the best available research with clinical expertise in the context of patient characteristics, culture, and preferences". Three main elements - best available research; clinical expertise; and patient preferences, values and context - will be the basis of the recommendations proposed later in the paper.

\section{AVAILABLE RESEARCH}

Regarding best available research, there is a growing body of evidence, including meta-analysis, systematic and integrative reviews, experiments and less rigorous studies as well, that supports using music as a tool to achieve positive changes in outcomes of neonates and their parents. According to research conducted to date, using live or recorded music, together with other types of music-based interventions, has a measurable positive physiological and behavioral impact on infants and their parents' outcomes during hospitalization. However, the effect is short-term (for more details: Ullsten, Eriksson, Klässbo, \& Volgsten, 2018; Stegeman, Geretsegger, Phan Quoc, Riedl, \& Smetana, 2019).

Regarding children, MT can contribute to regulating physiological parameters of preterm babies (e.g., regulating heart rate, improving oxygen saturation levels), improving feeding ability and weight gain (e.g., regulating sucking patterns, increasing breastfeeding volume and caloric intake), and regulating behavior states (Anderson \& Patel, 2018; Bieleninik et al., 2016; Bieleninik \& Gold, 2014; Hartling et al., 2009; Haslbeck, 2012; Haslbeck \& Stegemann, 2018; van der Heijden et al., 2016; Hodges \& Wilson, 2010; Standley, 2012).

Regarding parents, MT can be focused on their specific needs and provided in a separated form (Roa \& Ettenberger, 2018) and has the potential to reduce parental stress, increase well-being, and improve coping skills. On the other hand, MT can also be centered around the relationship between parents and their infants as well as reciprocal regulation (Cevasco, 2008; Ettenberger et al., 2014, Ettenberger, Rojas Cárdenas, Parker, \& Odell-Miller, 2017; Loewy, 2011; Whipple, 2000). Lowered levels of parental stress were observed in mothers who took part in MT. Additionally, increased well-being and improved coping were noted, and MT positively impacted relationships with their infants (Cevasco, 2008; Ettenberger et al., 2014, 2017; Loewy, Stewart, Dassler, Telsey, \& Home, 2013). To be more specific, a large, favorable effect of MT on respiratory rate (mean difference: -3.91 / min, $95 \%$ CI: -7.80 to -0.03 ) and maternal anxiety (standardized mean difference: -1.82 , 95\% CI: -2.42 to -1.22 ; Bieleninik et al., 2016) was found in a recent rigorous meta-analysis based on studies with 964 infant participants and 266 parent participants.

A new area that needs closer examination is the potential benefits of MT for preterm babies after their stay at the NICU. However, MT for preterm neonates and their families after hospitalization is a very new field of scientific interest and it requires scientific investigation; the practice seems to give some promising prospects. At this point, there is almost no research on this area. However, there are some attempts of practicing MT at home (https://www.modern- 
healthcare.com/article/20190119/NEWS/190119919/ music-therapy-program-for-preemies-to-offer-hometherapy). To our best knowledge, the only study currently available is a pilot study conducted by Calderon-Noyand and Gilboa (2019). The results of the study suggest that using the model designed by the authors, called Communicative Parental Efficacy (COPE) with music, which combines supportive listening to the mother and active vocal and musical interactions between her and the baby, can be beneficial to the dyad. However, their findings are based on only two cases of dyads and qualitative measures only.

\section{CLINICAL EXPERTISE}

The second component of EBP is clinical expertise. Clinical expertise is a factor that differs from one clinician to another, and therefore it is highly individual. Nonetheless, the expertise - too some extent - arises from the training the therapist received, together with specific personal aspects, such as years of practice, personality, etc. To somehow standardize the training procedures, specialized training programs in NICU MT were established.

Advanced training in this specific clinical field is offered through two institutions in the United States of America (National Institute for Infant and Child Medical Music Therapy at Florida State University in Tallahassee, Florida, and Louis Armstrong Department of Music Therapy, Mount Sinai Beth Israel in New York), and one in Switzerland (Haslbeck \& Costes, 2011). In all cases, the training is based on collaboration between the academic institution and hospital and consists of theoretical and practical components.

\section{PATIENT PREFERENCES, VALUES AND CONTEXT}

Characteristics and values are highly individual, but context seems to be more general. It can be considered on different levels, from cultural and political, to familial and institution-related. The clinical choices regarding this area are therefore requiring therapists' sensitivity to specific communities that are shaped by more general conditions (country, health system) and more specific ones (hospital and unit policies, patients' individual needs, etc.).

\section{MUSIC THERAPY IN POLISH NICUS - CURRENT SITUATION}

The present situation regarding MT applications in Poland is in the early stage of development for this complementary form of therapy, and there are cer- tain misunderstandings in the perception of this discipline in medical communities. Some Polish hospitals claim (on the websites) to offer MT as a part of their services, but what they provide is in fact is just playing recorded music from an audio system on the ward. This kind of treatment does not meet the criteria of MT in general (Konieczna-Nowak, 2018; Stachyra, 2020, in press). Several medical publications include information on MT, but closer examination shows that they are in fact referring to music listening and music-based interventions with no relation to actual, evidence-based MT standards and research results (Hirle, Wróbel, \& Parkita, 2018; Pilch, 2012). As previously, mentioned, research shows that only individualized interventions might have positive results; therefore this form of music-based stimulation might well not just be neutral but even harmful.

Until 2018, there was no properly trained NICU music therapists in Poland. General MT training offered during the bachelor/master study program is too broad and not sufficient for developing competencies and specialized knowledge crucial for the NICU work. In the country, there are currently three main academies of music which provide MT training at the bachelor and master levels (Katowice, Wroclaw, Łódź) and there are a few other institutions which offer postgraduate courses (in Lublin and Cracow). International collaborations allow Polish MT departments to uphold world standards, but - until now - there has not been any neonatal intensive care MT training provided in the country, and music therapists who are interested in this area need to find training abroad (Bieleninik \& Ghetti, 2019).

Also, until very recently, there was no research regarding NICU MT in Poland (Bieleninik \& Ghetti, 2019). In 2018, an opportunity arose to join the international project Longitudinal Study of music Therapy's Effectiveness for Premature infants and their caregivers (LongSTEP), which included, apart from Poland, also Norway, Colombia, Argentina, and Israel. For this project purpose, the Polish team operates between three institution: (1) the Institute of Psychology of the University of Gdansk, (2) the Department of Music Therapy of the Karol Szymanowski Academy of Music in Katowice, and (3) the Neonatology Department of the Municipal Hospital in Ruda Śląska, where the LongSTEP project is currently being conducted. The LongSTEP protocol was feasibility-tested in Poland prior to initiating recruitment for the definitive project (Bieleninik, Konieczna-Nowak, Knapik-Szweda, \& Kwaśniok, 2020). Researchers involved in this project predict that outcomes from the Polish arm of the LongSTEP project should provide insight on how to implement MT in Poland's neonatal health system.

The motivation behind taking up this topic is the fact that no clinical guidelines or recommendations referring to MT in Polish neonatal settings have been
Music therapy for preterm infants: recommendations for clinical practice in Poland 
Łucja Bieleninik, Ludwika Konieczna-Nowak, Sara KnapikSzweda, Justyna Kwaśniok provided so far. At this point, clinical implications regarding MT that would incorporate Polish NICUs' specific conditions (such as space arrangement, organization of medical staff's work and procedures, financial possibilities, standards of care), current research findings, and healthcare trends acknowledging the presence of family should be constructed to ensure safe and the most effective practice in the future.

The aim of this paper is to present recommendations for clinical practice that are based on current research evidence and currently available clinical experiences in Polish conditions and consider both phases: during the NICU stay and beyond the NICU. Relating to the previously presented information, the framework and recommendations formulated here might be considered EBP, because they integrate current research and clinical expertise which is not sufficient, but best available. Also, context and patients' characteristics were taken into consideration.

This proposition has grown from practical experiences gathered during 191 sessions conducted during children's NICU stays with 20 families, and 49 sessions held after the children were discharged, all as a part of the LongSTEP. The sessions were led by two music therapists, who received the appropriate, advanced international training in the model developed by Joanne Loewy called Rhythm, Breath, Lullaby (RBL). The training took place at the University Hospital in St. Polten, Austria. They were also trained in the study protocol procedures and treatment guidelines for each of the two MT interventions (MT during NICU hospitalization and MT post-discharge from hospital) of the LongSTEP project.

The structure of the recommendations will include: referral suggestions, needs and goals, treatment procedures, evaluation strategies as formulated similarly to other kind of guidelines proposed in MT literature regarding different populations (NockerRibaupierre, 2013; Stouffer, Shirk, \& Polomano, 2007).

\section{MUSIC THERAPY DURING NICU STAY - RECOMMENDATIONS FOR PRACTICE}

\section{REFERRALS - TARGET POPULATION, NEEDS, GOALS}

Referring the neonate and their family to MT should always involve a medical staff member's decision. Although in some cases self-referral by a parent could be an initial moment, it is crucial that the doctor makes the final decision whether or not the child is medically stable enough to be exposed to additional stimulation. It is impossible to determine at which postmenstrual age or weight the preterm baby will be ready for it, so an individual assessment should be performed every time. However, some general criteria for referrals are suggested in MT literature. These eligibility criteria concern: medical parameters (of the neonate) as well as behavioral and psychological components (of the neonate and the primary caregiver) together with informed consent from the parents.

- Medical parameters include: 28 weeks of gestational age as minimum, medical stability.

- Behavioral aspects are as follows: problems with sleep, feeding, breathing, emotional regulation, irritability, crying.

- On the caregiver's side: anxiety, depression, lack of confidence, problems with bonding (NockerRibaupierre, 2013).

Therefore, the goals of MT would be a reflection of the family's needs, and thus could include the following:

- for the neonate to improve sleep, increase feeding, stabilize breathing, promote emotional regulation, decrease irritability and crying,

- for the parents or other primary caregivers: to alleviate anxiety and depression, provide with means for bonding and building self-confidence (Nocker-Ribaupierre, 2013).

\section{TREATMENT; SPACE ARRANGEMENTS, INTERVENTION CONTENT, MUSIC CHARACTERISTICS, PROCEDURES}

Specific space arrangements depend on the MT techniques that would be used. Before choosing the most appropriate place, some practical decisions must be made. As mentioned before, every newborn might be at a different developmental stage and might have different sensory needs; therefore receptive MT techniques would not only be suited to the needs of some children, but also they could even be harmful to others. While in active MT participants are involved in active music making (composing, performing, improvising, etc.), receptive methods are based on music listening for different purposes (Konieczna-Nowak, 2013); therefore, active MT techniques seem more appropriate than the receptive ones. Intervention content should vary depending on the specific needs and developmental stage of the neonate and the needs of the family. The eclectic approach using different strategies seems to be the most flexible and therefore addresses the individual needs the best. MT sessions should be directed towards specific dyads of neonate and the primary care-giver.

Music, and subsequently MT, has to be considered in a broader context of sounds that surround preterm babies at the hospitals, and which should be neurologically safe for neonates at different stages of development. Soundscapes of the NICUs, in terms of noise, control of noise, and sounds that possibly could be positively stimulating, are receiving more 
and more attention in Polish medical communities (Cedrowska-Adamus \& Gulczyńska, 2018).

Considering the instructions related to the environment, specific levels of sound on NICUs are defined. The maximum sound volume in the room is $45 \mathrm{~dB}$ with short noises not louder than $65 \mathrm{~dB}$. The level recommended for sleep periods is $35-45 \mathrm{~dB}$. Therefore, it is suggested that any devices such as radios, TVs and toys which make noise should be eliminated. Talking and singing to the baby performed by parents is indicated as appropriate aural stimulation, which supports MT (Borszewska-Kornacka, 2019; Cedrowska-Adamus \& Gulczyńska, 2018).

In most Polish NICUs a rooming-in system is implemented; however, in many cases rooms are not designed for use by a single family and must accommodate multiple mother-child dyads. It makes MT practice difficult, as the best environment would be the private space, allowing for intimacy. Moreover, when MT is directed towards one family, it might constitute undesired additional stimulation for other newborns, as they are sleeping or are breastfed. Also, other people, such as visitors and medical staff, might interrupt the sessions. Therefore, the most desirable location for MT sessions in this context would be a separate room dedicated to MT, where the family could go in for the session (if possible). However, in such a situation, it would not be possible to refer all preterm babies to MT, as moving them from one room to another cannot be recommended due to their medical condition. Practical negotiations have to be done in clinical situations given, and trying to find the best possible solution should be done case by case.

MT is not recommended before 26 weeks after menstrual age. As the baby grows, very careful attempts might be taken, with soft singing and toning only (Ghetti et al., 2019; Haslbeck, 2014; Haslbeck, Bucher, Bassler, \& Hagmann, 2017). Singing and humming should be adjusted to infants' breathing pattern, and should remain low in dynamics and tempo, preferably on the interval of a third. Although wordless singing seems to be most appropriate for a child, it was observed that simple lullabies or well-known songs preferred by the parents modified into lullaby style are more easily accepted by caregivers. Also, composing personalized lullabies and songs to the well-known or original melodies, with words put together by parents might be a good tool for supporting and empowering parents, and providing them with the opportunity to focus on the child. Through creating words and melodies, with the therapist's help, parents build relationship and bond with their newborn on the stage, where possibilities for interactions are limited. At this time use of instruments is not recommended, and if decided otherwise due to the parents' needs, it should be limited. MT sessions might occur during kangaroo care or breastfeeding attempts, but very cautiously, to avoid overstimulation.
From 32 weeks to below 36 PMA, the music therapist can try to apply cautious infant-directed speech and music. Children's songs might be introduced with careful observation of the infant's reactions. The choice of the songs should be consulted with parents, and - if possible - the repertoire should be suggested by them. The infant's facial expression and gesticulation should be considered cues on how to sing. The music should be interactive, slightly more dynamic, and it should change in response to the child's behavior. Soft sounding instruments, such as nylon string guitar, ocean disc or gato-box (Loewy et al., 2013), as well as delicate rattles, can be used, if the child can tolerate such a sound. Also a monochord can generate relaxing sounds and give a vibro-acoustic stimulation (Haslbeck, 2017). The older the child, the more focus should be put on musical exchange.

The time of the intervention should be tailored individually, depending on the child's medical condition and GA. Based on the experiences of Polish music therapists, sessions that are not longer than 30 minutes are most efficient for neonates. Each session should be preceded and followed by a conversation with the caregiver. The sessions should occur as often as possible during the child's hospitalization, preferably twice or 3 times a week (as suggested in the literature: Loewy et al., 2013). The period during which the intervention is provided should be as long as a child is hospitalized in neonatal settings.

In practice, it might happen that a child will be transported to another setting or unit. When the child is admitted to a different place, the medical staff should again assess whether it is possible to continue MT or whether it should be discontinued due to changes in the child's medical status. Care should be taken to maintain day-by-day contact between the music therapist and the medical staff to be sure that the child is stable and ready for MT continuation.

During an MT session an infant can stay in the crib/incubator, or - preferably - is held by the parent in the position which is most comfortable and allows for contact between the parent and a child. The therapist should be standing or sitting close to the infant and the parent. If the parent is not present and medical staff allows it, the therapist might hold the child. The therapist should wear a medical apron and have had their hands and instruments disinfected due to the safety reasons regulated by hospital rules and policies.

The decision on which music to use depends on the music therapist's knowledge and experience, but it should be consulted with the caregivers and flexibly adjusted to the given situation and the caregiver's preferences. At early stages, improvisatory humming, toning and singing are recommended. Later on, ready musical material, such as lullabies and children's songs, should be incorporated. The adaptations and personalized versions of ready songs
Music therapy for preterm infants: recommendations for clinical practice in Poland 


\section{Łucja Bieleninik, Ludwika} Konieczna-Nowak, Sara KnapikSzweda, Justyna Kwaśniok are also suggested (e.g. Na Wojtusia z popielnika... with inserted name of the actual child, the melody of Panie fanie with the words of welcoming the child, etc.). Modifying parent preferred songs from different genres into infant's appropriate musical material (slower tempo, soft dynamics, loosened rhythmic structure) can also be performed. It is very important that the music feels comfortable for the parents and is culturally appropriate within the environment of the given family (Shoemark \& Ettenberger, 2020).

The person delivering the music should eventually be the parent; however, in the Polish community, singing is not a comfortable activity for most adults. Therefore, at the beginning, it is the music therapist who provides singing and invites and instructs the caregiver to join in. When caregivers are comfortable enough to make music themselves, the music therapist should fade slowly and gradually. Apart from delivering the music and/or instructing the parent, the music therapist should also pay attention and point out to the parents what reactions can be observed and how these reactions can be responded to.

\section{EVALUATION AND DOCUMENTATION}

The MT process should be monitored and described in detail on many medical/physiological levels. Heart rate, respiratory rate and oxygen saturation of a newborn should be checked and noted before and after each session, it should also be taken into consideration during the session, if possible. It is important that the music therapists monitor the vital signs and adjust the therapy to the current condition of the newborn. Also, behavioral aspects and child's responses and their triggers should be listed. In addition, the caregiver's psychological health might be taken into account as well as the child's. Mothers' mental state can be measured in many different ways, e.g. on a Likert-type scale, in a descriptive manner, or, when the case requires more in-depth analysis, using psychological assessment tools, such as Generalized Anxiety Disorder-7 (screening tool of anxiety) or the Edinburgh Postnatal Depression Scale (screening tool for depression). The assessment notes should be available for medical staff, and when something possibly important is observed, it should be reported to the medical staff in line with the communication procedures in use at the specific NICUs. The perfect situation would be if music therapists were to be a part of an interdisciplinary team of NICU staff and were to participate in daily rounds at the unit. Interviews with parents are also an invaluable source of information about the newborn and the family system. Whenever possible, an in-depth discussion with the parents should be conducted to gather information on their perception of the child and their musical resources. However, this informa- tion might be useful mostly for the music therapist, and does not necessarily need to be included in the child's medical documentation.

\section{MUSIC THERAPY AFTER DISCHARGE FROM HOSPITAL - RECOMMENDATIONS FOR PRACTICE}

\section{REFERRALS - TARGET POPULATION, NEEDS, GOALS}

Transition from NICU to home is a joyful yet challenging moment for the family. At this point, parents experience a lot of anxiety and uncertainty; therefore, home visits and further support are the key components in the after-discharge phase (Boykowa, 2016; Lopez, Anderson, \& Feutchinger, 2012). Referrals after discharge should be self-requested, but can be advised and suggested by medical staff, when parents seem to need additional support and counseling regarding bonding with the infant and their psychological functioning. Once a month over a period of half a year would be the optimal course of continuing the treatment; however, in some cases, where the depression risk is higher, more frequent meetings (even weekly) might be appropriate and effective, as this schedule allows for a more steady therapeutic process to occur.

The moment at which the family is ready for receiving MT at home varies from case to case. It should be remembered that time is needed to adjust to the new situation with a child in a family everyday routine. Some families require support at this stage, but others need peace and quiet and prefer limiting interactions with the outside world. Postpartum depression becomes a risk factor that also impacts the attitudes of mothers towards other people, including therapists. Therefore, the first sessions should be provided in a flexible way, with respect to the unexpected changes in schedulesAt this stage, the goals of MT start to vary more and more, as each infant and parents develop at a different pace and in a different direction. The physiological aspects are less crucial, but psychological mechanisms such as bonding and reciprocity should be monitored and stimulated. MT can offer a wide range of interventions that focus on interaction and communication between the parents and the child as well as providing relaxation strategies. Continuously, educating and instructing parents how to use music in their everyday routine also form an important aspect of the treatment process.

At this stage, goals can focus around (but not be limited to) areas regarding both the family as a system, and the infant and the caregivers as separate individuals, such as:

- interaction between family members,

- communication,

- child's arousal changes (relaxation, activation), 
- bonding,

- play skills,

- sensory stimulation,

- mothers' mood (reducing stress and depression risk).

\section{TREATMENT; SPACE ARRANGEMENTS, INTERVENTION CONTENT, MUSIC CHARACTERISTICS, PROCEDURES}

Sessions can be offered at home or at an MT private practice location at the parents' convenience. Both options have advantages and disadvantages for the family. Having a stranger at home is something that is not always comfortable for the parents, yet travelling with a small baby to some other place also requires additional effort and time.

In this phase, the therapist should follow individual development of the child providing them with a richer and more varied musical environment. Multimodal stimulation, such as using visual prompts for visual tracking, or different instruments for auditory perception, might be incorporated.

At this stage parents' musical preferences should play a more important role. The interventions based on so-called songs of kin should be incorporated. A song of kin is the song that has a special meaning for the family and is adapted by the music therapist into a lullaby-like style. Following the developmental changes of the child, the therapist might use more songs and improvisation structures that stimulate the activity of all family members. Similarly to the previous stage, the music therapist should mostly instruct parents to perform musical interventions.

Also, the verbal element of the sessions is important. While in the NICU, parents have access to many members of the medical staff to which they could talk. After discharge, they might feel the need to share their current experiences, fears and hopes. Parent counseling should not dominate the musical component, but it can definitely play an important role in the therapeutic process.

Regarding frequency of the sessions, it needs to be explored more. In the LongSTEP, MT was offered approximately once a month during the first half a year following discharge home. In some cases it seemed enough, while in others, more frequent sessions would be beneficial. Therefore, we would recommend sessions twice a month, but in a flexible manner, adjusted to the caregiver's needs and possibilities.

\section{EVALUATION AND DOCUMENTATION}

Evaluation can be performed in a narrative manner, with parents' self-reports at the base. Interviewing and ongoing monitoring of the situation through in- formal conversations should be continued. Formal measures, such as tests and scales regarding the development of the child, emotional state of the parents, or the bonding processes, can be performed if needed.

\section{FINANCIAL ASPECTS AND LOGISTICS}

Music therapy is not a highly expensive service in Poland. The average costs of a private one-to-one session is EUR 20 (source: private correspondence with Krzysztof Stachyra, president of the Polish Music Therapists Association, 2020). Introducing it to the care package for premature children might even reduce costs of other treatment procedures and medical resources (decrease or elimination of sedation, reduction in procedural times) in pediatric healthcare (DeLoach, 2005). Nevertheless, in Polish hospitals there might be difficulties in finding financial support. During the post-discharge phase, MT would need to be privately covered, although some organizations (such as associations and charities of different kinds) might raise funds and sponsor such a service.

In terms of logistics, team work is a highly important factor. During the time of hospitalization, it seems crucial to include the music therapist in the treatment team and keep them included in the information flow. This kind of collaboration allows for effective work and improves the quality of services provided to the patients. It also helps in proper planning and scheduling sessions.

After discharge, the cooperation between the music therapist and parents is also very important. At this stage, parents serve as the link between all the specialists who work with the newborn and the music therapist. Forwarding information regarding current treatments and goals allows for coordinating the work and making it as cohesive and effective as possible.

\section{OVERALL RECOMMENDATION FOR PRACTICE}

Based on research and own experience gathered during the LongSTEP project, we recommend implementing MT to improve patient outcomes by using the suggestions mentioned above.

Summing up practical considerations, it should be remembered that families:

- are often unfamiliar with MT and need to be explained properly what to expect, what the possible benefits and risks are, and to what extent their involvement is required,

- struggle with medical terminology, equipment, diagnosis, procedures; therefore the explanation should be delivered in easy-to-understand language,
Music therapy for preterm infants: recommendations for clinical practice in Poland 


Łucja Bieleninik,
Ludwika
Konieczna-Nowak,
Sara Knapik-
Szweda, Justyna
Kwaśniok

- do not necessarily understand the daily practice and routine at the NICU; therefore scheduling should be done with them and the medical team.

At the same time, MT sessions during and after NICU care should always be:

- tailored to individual needs,

- interactive and flexible,

- based on parent/child work (instructional),

- consulted with the team (medical during NICU, family and other professionals if possible, after discharge).

\section{CONCLUSIONS}

Music therapy is an innovative complementary nonpharmacological treatment which could be provided in neonatal departments of the Polish healthcare system. The application should be fully professional, to ensure safety and best services for the recipients. This intervention dedicated to premature babies hospitalized in NICUs and their families is still in the phase of intense development not only in Poland, but also worldwide. Clinical research, which would make it possible to call it a fully evidence-based perspective, is growing. For now, the findings based on international samples are promising and clinical experiences bring positive results for patients hospitalized in NICUs.

Despite preliminary evidence indicating their beneficial effects for both babies and their caregivers during the neonatal period, "best practices" are not always effective in new or different situations. In a country like Poland, where MT is far from being a part of standard care in the NICU and beyond (Bieleninik \& Ghetti, 2019), some steps should be taken to implement best possible strategies within a pragmatic, feasible perspective.

The recommendations we proposed here are - as mentioned before - based on current available research, expertise of two professionally trained music therapists and patients' characteristics, values and context. All currently available research projects were conducted in different European and American countries; therefore, the results must be interpreted carefully and with the awareness that they might be culturally specific, and hence not fully applicable to other cultures. In this paper, we tried to frame the recommendations for the specific Polish context.

Different settings and populations present a range of cultural, economic, and other environmental circumstances that affect behavior and outcomes. Thus, even evidence-based practice does not guarantee success, if both scientific evidence and experiential knowledge of what would likely work in a particular context are not respected. We present culture-appropriate and clinically feasible suggestions; however, the more research is conducted, the more adjusted and detailed information will there be, allowing us to get to the point at which setting precise clinical guidelines is possible.

This perspective article presents recommendations for practice for music therapists in Poland as well as other countries with a similar cultural context. However, more national trials, taking into consideration Polish cultural and practical aspects, are still very much needed.

\section{LIMITATIONS}

The limitations of these recommendations include a relatively small number of families which participated in music therapy during the NICU stay and after discharge in Poland. Also, they are based on experiences of working in one hospital and one NICU setting. However, combined with literature search and research results, the ideas presented create the best possible recommendations considering the current state of the art.

\section{RefERENCES}

Abromeit, D. (2003). The newborn individualized developmental care and assessment program (NIDCAP) as a model for clinical music therapy interventions with premature infants. Music Therapy Perspectives, 21, 60-68. https://doi.org/10.1093/mtp/21.2.60

Ainsworth, M. D. S., Blehar, M. C., Waters, E., \& Wall, S. N. (1978). Patterns of attachment: A psychological study of the strange situation. Hilsdale NJ: Erlbaum.

Anderson, D. E., \& Patel, A. D. (2018). Infants born preterm, stress, and neurodevelopment in the neonatal intensive care unit: might music have an impact? Developmental Medicine \& Child Neurology, 60, 256-266. https://doi.org/10.1111/dmcn.13663

Berard, A., Le Tiec, M., \& De Vera, M. (2012). Study of the costs and morbidities of late preterm birth. Archives of Disease in Childhood-Fetal and Neonatal Edition, 97, F329-F334.

Bernard-Bonnin, A. (2004). Psychosocial Paediatrics Committee of Canadian Society of Pediatrics, Canadian Paediatric Society. Maternal depression and child development. Paediatrics \& Child Health, 9, 575-583. https://doi.org/10.1093/pch/9.8.575

Bidzan, M., \& Bieleninik, Ł. (2013). Psychomotor development of preterm babies in the context of biomedical predictors in a Polish sample. Health Psychology Report, 1, 18-33. https://doi.org/10.5114/ hpr.2013.40466

Bidzan, M., Bieleninik, Ł., Zdolska, A., \& Salwach, D. (2009). Bond with a child in the prenatal period in case of prematurely born children. In K. Turowski (Ed.), Wellness and success (vol. 3, pp. 35-54). Lublin: NeuroCentrum. 
Bieleninik, Ł. (2012). Dzieci przedwcześnie urodzone w percepcji matek [Mothers' perception of prematurely born children]. Gdansk: Harmonia Universalis.

Bieleninik, Ł., Bidzan, M., \& Salwach, D. (2009). The premature birth trauma and the parents' quality of life in the light of the S. Allen and A. Michalos's models. In G. Olchowik (Ed.), Wellness and success (vol. 2, pp. 39-52). Lublin: NeuroCentrum.

Bieleninik, Ł., \& Ghetti, C. (2019). Music therapy for preterm infants and their parents: a path forward for research in Poland. Roczniki Psychologiczne/Annals of Psychology, 22, 135-150. https://doi. org/10.18290/rpsych.2019.22.2-3

Bieleninik, Ł., Ghetti, C., \& Gold, C. (2016). Music therapy for preterm infants and their parents: a meta-analysis. Pediatrics, 138, e20160971. https:// doi.org/10.1542/peds. 2016-0971

Bieleninik, Ł., \& Gold, C. (2014). Early intervention for premature infants in neonatal intensive care unit. Acta Neuropsychologica, 12, 185-203. https:// doi.org/10.5604/17307503.1111845

Bieleninik, Ł., Konieczna-Nowak, L., Knapik-Szweda, S., \& Kwaśniok, J. (2020). Evaluating Feasibility of the LongSTEP (Longitudinal Study of Music Therapy's Effectiveness for Premature Infants and Their Caregivers) Protocol with a Polish Cohort. Nordic Journal of Music Therapy. https://doi.org/10.1080/080981 31.2020.1781233

Blencowe, H., Cousens, S., Chou, D., Oestergaard, M., Say, L., Moller, A. B., Kinney, M., Lawn, J., \& on behalf of the Born Too Soon Preterm Birth Action Group (2013). Born Too Soon: The global epidemiology of 15 million preterm births. Reproductive Health, 10 (Suppl 1), S2. doi: 10-1186/1742-4755-10S1-S2

Borszewska-Kornacka, M. (2019). Standardy opieki medycznej nad noworodkiem w Polsce - zalecenia Polskiego Towarzystwa Neonotologicznego (wyd. 3) [Standards of medical care for a newborn in Poland - recommendations of the Polish Neonotological Society (3rd ed.)]. Warszawa: Polskie Towarzystwo Neonatologiczne.

Bowlby, J. (1997). Attachment and loss. Vol. 1. London: Pimlico.

Boykowa, M. (2016). Transition from hospital to home in preterm infants and their families. The Journal of Perinatal and Neonatal Nursing, 30, 270-272. https://doi.org/10.1097/JPN.0000000000000198

Calderon-Noyand, G., \& Gilboa, A. (2019). COPE with music: A preliminary examination of a model with mothers and their premature babies, post NICU discharge. Paper presented at the $11^{\text {th }}$ European Music Therapy Conference, Aalborg, Denmark. Abstract retrieved from http://people.hum.aau. dk/ hanne/EMTC19\%20ABSTRACTS.pdf

Cedrowska-Adamus, W., \& Gulczyńska, E. (2018). Kontrola poziomu dźwięków na oddziale noworodkowym [Control of noise level in the neonatal intensive care unit]. Postępy Neonatologii, 24, 129-133. https:// doi.org/10.31350/postepyneonatologii/2018/2/

Cevasco, A. M. (2008). The effects of mothers' singing on full-term and preterm infants and maternal emotional responses. Journal of Music Therapy, 45, 273-306. https://doi.org/10.1093/jmt/45.3.273

DeLoach, W. D. (2005). Procedural-Support Music Therapy in the healthcare setting: A Cost-effectiveness analysis. Journal of Pediatric Nursing, 20, 276-284. https://doi.org/10.1016/j.pedn.2005.02.016

Doroszewska, A. (2017). Raport z monitoringu oddziatów położniczych. Medykalizacja porodu w Polsce [Report on the monitoring of maternity wards. Medicalization of childbirth in Poland]. Warszawa: Fundacja Rodzić po Ludzku.

Ettenberger, M., Odell-Miller, H., Cardenas, C. R., Serrano, S. T., Parker, M., \& Camargo Llanos, S. M. (2014). Music therapy with premature infants and their caregivers in Colombia-A mixed methods pilot study including a randomized trial. Voices: A World Forum for Music Therapy, 14. https://doi. org/10.15845/voices.v14i2.756

Ettenberger, M., Rojas Cárdenas, C., Parker, M., \& Odell-Miller, H. (2017). Family-centred music therapy with preterm infants and their parents in the Neonatal Intensive Care Unit (NICU) in $\mathrm{Co}^{-}$ lombia - A mixed-methods study. Nordic Journal of Music Therapy, 26, 207-234. https://doi.org/10.1080/ 08098131.2016.1205650

Ghetti, C., Bieleninik, Ł., Hysing, M., Kvestad, I., Assmus, J., Romeo, R., Ettenberger, M., Arnon, S., Vederhus, B. J., Söderström Gaden, T., \& Gold, C. (2019). Longitudinal study of music therapy's effectiveness for premature infants and their caregivers (LongSTEP): protocol for an international randomised trial. BMJ Open, 9, e025062. https://doi. org/10.1136/bmjopen-2018-025062

Hall, S., Philips, R., \& Hynan, M. (2016). Transforming NICU care to provide comprehensive family support. Newborn and Infant Nursing Reviews, 16, 69-73. https://doi.org/10.1053/j.nainr.2016.03.008

Hanson-Abromeit, D., \& Colwell, C. (Eds.). (2010). Effective clinical practice in music therapy: Medical music therapy for pediatrics in hospital settings. AMTA Monograph Series. Silver Spring, MD: American Music Therapy Association.

Hart, S. (2011). The impact of attachment: Developmental neuroaffective psychology. New York, NY: WW Norton.

Hartling, L., Shaik, M. S., Tjosvold, L., Leicht, R., Liang, Y., \& Kumar, M. (2009). Music for medical indications in the neonatal period: a systematic review of randomised controlled trials. Archives of Disease in Childhood. Fetal and Neonatal Edition, 94, F349-F354. https://doi.org/10.1136/adc.2008.148411

Haslbeck, F. B., Bucher, H. U., Bassler, D., \& Hagmann, C. (2017). Creative music therapy to promote brain structure, function and neurobehavioral out-
Music therapy for preterm infants: recommendations for clinical practice in Poland 
Łucja Bieleninik, Ludwika Konieczna-Nowak, Sara KnapikSzweda, Justyna Kwaśniok comes in preterm infants: a randomized controlled pilot trial protocol. Pilot and Feasibility Studies, 3, 36. https://doi.org/10.1186/s40814-017 0180-5

Haslbeck, F. B., \& Stegemann, T. (2018). The effect of music therapy on infants born preterm. Developmental Medicine \& Child Neurology, 60, 217. https://doi.org/10.1111/dmcn.13677

Haslbeck, F. (2017). Three little wonders: Music therapy with families in neonatal care. In S. L. Jacobson \& G. Thompson (Eds.), Music Therapy with Families. Therapeutic Approach and Theoretical Perspectives (pp. 19-45). London: Jessica Kinglsey Publishers.

Haslbeck, F. (2014). The interactive potential of creative music therapy with premature infants and their parents: a qualitative analysis. Nordic Journal of Music Therapy, 23, 36-70. https://doi.org/10. 1080/08098131.2013.790918

Haslbeck, F. B. (2012). Music therapy for premature infants and their parents: an integrative review. Nordic Journal of Music Therapy, 21, 203-226. https://doi.org/10.1080/08098131.2011.648653

Haslbeck, F., \& Costes, T. (2011). Advanced training in music therapy with premature infants: Impressions from the United States and a starting point for Europe. British Journal of Music Therapy, 25, 21-33. https://doi.org/10.1177/135945751102500203

Haslbeck, F. B., Nöcker-Ribaupierre, M., Zimmer, M. L., Schrage-Leitner, L., \& Lodde, V. (2018). Music therapy in neonatal care: A framework for Germanspeaking countries and Switzerland. Music \& Medicine, 10, 214-224.

Hirle, L., Wróbel, M., \& Parkita, A. (2018). Znaczenie muzykoterapii w położnictwie i neonatologii [Significance of music therapy in obstetrics and neonatology]. Pieleggniarstwo XXI wieku, 2, 58-62.

Hodges, A. L., \& Wilson, L. L. (2010). Effects of music therapy on preterm infants in the neonatal intensive care unit. Alternative Therapies in Health and Medicine, 16, 72-73.

Huhtala, M., Korja, R., Lehtonen, L., Haataja, L., Lapinleimu, H., \& Rautava, P., on behalf of the PIPARI Study Group (2012). Parental psychological wellbeing and behavioral outcome of very low birth weight infants at 3 years. Pediatrics, 128, e937-e944. https://doi.org/10.1542/peds.2011-2411

Institute for Patient and Family-Centered Care (2010). www.ipfcc.org/about/pfcc.html (2019-07-31).

Jolley, J., \& Shields, L. (2009). The evolution of familycentered care. Journal of Pediatric Nursing, 24, 164170. https://doi.org/10.1016/j.pedn.2008.03.010

Konieczna-Nowak, L. (2013). Wprowadzenie do muzykoterapii [Introduction to music therapy]. Kraków: Impuls.

Konieczna-Nowak, L. (2018). Muzykoterapia. Sztukanauka-człowiek [Music Therapy. Art-science-man]. Katowice: Wydawnictwo Akademii Muzyczne im. Karola Szymanowskiego.
Kopeć, A., Aftyka, A., Humeniuk, E., Rybojad, B., \& Rozalska-Walaszek, I. (2016). Hospitalizacja dziecka w Oddziale Intensywnej Terapii Noworodka - doświadczenia rodziców [Hospitalization of a child in the Neonatal Intensive Care - parents' experiences]. Current Problems of Pyschiatry, 17, 24-30.

Loewy, J. (2011). Music therapy for hospitalized infants and their parents. In J. Edwards (Ed.), Music therapy and parent-infant bonding (pp. 179-190). London: Oxford University Press.

Loewy, J., Stewart, K., Dassler, A. M., Telsey, A., \& Homel, P. (2013). The effects of music therapy on vital signs, feeding, and sleep in premature infants. Pediatrics, 131, 902-918. https://doi. org/10.1542/peds.2012-1367

Lopez, G., Anderson, K., \& Feutchinger, J. (2012). Transition of premature infants from hospital to home life. Neonatal Network, 31, 207-214. https:// doi.org/10.1891/0730-0832.31.4.207

Łuczak-Wawrzyniak, J., Czarnecka, M., Konofalska, N., Bukowska, A., \& Gadzinowski, J. (2010). Holistyczna koncepcja opieki nad wcześniakiem lub (i) dzieckiem chorym - pacjentem Oddziału Intensywnej Terapii Noworodka i jego rodzicami [The concept of holistic care over premature and/ or sick infant - NICU patient and its parents]. Perinatologia, Neonatologia i Ginekologia, 3, 63-61. March of Dimes, PMNCH, Save the Children, WHO. (2012). Born Too Soon: The Global Action Report on Preterm Birth. C. P. Howson, M. V. Kinney, J. E. Lawn (Eds.), World Health Organization: Geneva.

Miles, S., Holditch-Davis, D., Schwartz, T., \& Scher, M. (2007). Depressive symptoms in mothers of prematurely born infants. Journal of Developmental \& Behavioral Pediatrics, 28, 36-44. https://doi. org/10.1097/01.DBP.0000257517.52459.7a

Nocker-Ribaupierre, M. (2013). Premature infants. In J. Bradt (Ed.), Guidelines for music therapy practice in pediatric care. Gilsum: Barcelona Publishers.

Pilch, D. (2012). Muzykoterapia [Music therapy]. In A. Pilewska-Kozak (Ed.), Opieka nad wcześniakiem [Caring for a premature baby]. Warszawa: Wydawnictwo Lekarskie PZWL.

Pilewska-Kozak, A., Skurzak, A., Bałanda-Bałdyga, A., Iwanowicz-Palus, G., Pięta, B., Werc, H., \& PiskorzSzymandera, M. (2009). Organizacja opieki nad noworodkiem wymagającym intensywnego nadzoru. In A. Pilewska-Kozak (Ed.), Opieka nad wcześniakiem [Caring for a premature baby]. Warszawa: Wydawnictwo Lekarskie PZWL.

Roa, E., \& Ettenberger, M. (2018). Music therapy self-care group for parents of preterm infants in the Neonatal Intensive Care Unit: A clinical pilot intervention. Medicines, 5, 134. https://doi.org/ 10.3390/medicines5040134

Separation and Closeness Experiences in Neonatal Environment (SCENE) research group (2016). Parent and nurse perceptions on the quality 
of family-centred care in 11 European NICUs. Australian Critical Care, 29, 201-209. https://doi. org/10.1016/j.aucc.2016.09.003

Shoemark, H., \& Ettenberger, M. (2020). Music therapy in neonatal care: Influences of culture. Dallas: Barcelona Pubslishers.

Singer, L., Salvator, A., Guo, S., Collin, M., Lilien, L., \& Baley, J. (1999). Maternal psychological distress and parenting stress after the birth of a very lowbirth-weight infant. JAMA, 281, 799-805. https:// doi.org/10.1001/jama.281.9.799

Smith, A., Caine, K., \& Hanson-Abromeit, D. (2018). Music therapy for neonatal intensive care. In Kinght, A., LaGasse A. B., \& Clair, A. (Eds.), Music Therapy: An Introduction to the Profession. Silver Spring: AMTA.

Sowada, C., Sagan, A., Kowalska-Bobko, I., BadoraMusiał, K., Bochenek, T., Domagała, A., DubasJakóbczyk, K., Kocot, E., Mrożek-Gąsiorowska, M., Sitko, S., Szetela, A., Szetela, P., Tambor, M., Więckowska, B., Zabdyr-Jamróz, M., \& van Ginneken, E. (2019). Poland: Health system review. Health Systems in Transition, 21, 1-235.

Stachyra, K. (2020). Muzykoterapia a interwencja przy pomocy muzyki [Music therapy and music-based intervention]. In Ł. Bieleninik \& L. KoniecznaNowak (Eds.), Muzykoterapia dzieci przedwcześnie urodzonych i ich rodzin: teoria i praktyka [Music therapy with premature children and their families: theory and practice]. Warszawa: Wydawnictwo Naukowe Scholar.

Standley, J. (2003). Music therapy with premature infants: Research and developmental interventions. Silver Spring, MD: The American Music Therapy Association.

Standley, J. (2012). Music therapy research in NICU: an updates meta-analysis. Neonatal Network, 31, 311316. https://doi.org/10.1891/0730-0832.31.5.311

Stegemann, T., Geretsegger, M., Phan Quoc, E., Riedl, H., \& Smetana, M. (2019). Music therapy and other music-based interventions in pediatric health care: An overview. Medicines, 6, 1-12. https://doi.org/10.3390/medicines6010025

Stouffer, J., Shirk, J., \& Polomano, R. (2007). Practice guidelines for music interventions with hospitalized pediatric patients. Journal of Pediatric Nursing, 22, 448-456. https://doi.org/10.1016/j.pedn. 2007.04.011

Troszyński, M., Niemiec, T., \& Wilczyńska, A. (2009). Ocena funkcjonowania trójstopniowej selektywnej opieki perinatalnej na podstawie analizy umieralności okołoporodowej wczesnej i cięć cesarskich w Polsce w 2008 roku [Assessment of three-level selective perinatal care based on the analysis of early perinatal death rates and cesarean sections in Poland in 2008]. Ginekologia Polska, 80, 670-677.

Ullsten, A., Eriksson, M., Klässbo, M., \& Volgsten, U. (2018). Singing, sharing, soothing-biopsychoso- cial rationales for parental infant-directed singing in neonatal pain management: A theoretical approach. Music \& Science, 1, 1-13. https://doi. org/10.1177/2059204318780841

Ullsten, A., Gaden, T. S., \& Mangersnes, J. (2019). Development of family-centered care informing Nordic neonatal music therapy. In L. O. Bonde \& K. Johansson (Eds.), Music in paediatric hospitals in the Nordic countries (pp. 1-25). Oslo: Skriftserie fra Senter for forskning i musikk og helse.

Underwood, M. A., Danielsen, B., \& Gilbert, W. M. (2007). Cost, causes and rates of rehospitalization of preterm infants. Journal of Perinatology, 27, 614-619.

van der Heijden, M. J. E., Oliai Araghi, S., Jeekel, J., Reiss, I. K. M., Hunink, M. G. M., \& van Dijk, M. (2016). Do hospitalized premature infants benefit from music interventions? A systematic review of randomized controlled trials. PLoS One, 11, e0161848. https://doi.org/10.1371/journal.pone. 0161848

Whipple, J. (2000). The effect of parent training in music and multimodal stimulation on parentneonate interactions in the neonatal intensive care unit. Journal of Music Therapy, 37, 250-268. https://doi.org/10.1093/jmt/37.4.250

WHO (1977). WHO: recommended definitions, terminology and format for statistical tables related to the perinatal period and use of a new certificate for cause of perinatal deaths. Modifications recommended by FIGO as amended October 14, 1976. Acta Obstetricia et Gynecologica Scandinavica, 56, 247-253.

https://www.modernhealthcare.com/article/20190119/ NEWS/190119919/music-therapy-program-for-preemies-to-offer-home-therapy (accessed 7 April 2020)
Music therapy for preterm infants: recommendations for clinical practice in Poland 